\title{
Approach for naso-orbito-ethmoidal fracture
}

\author{
Young In $\mathrm{Ha}^{1}$, \\ Sang Hun Kim², \\ Eun Soo Park², \\ Yong Bae Kim ${ }^{2}$ \\ ${ }^{1}$ Department of Plastic and \\ Reconstructive Surgery, Hallym \\ University Dongtan Sacred Heart \\ Hospital, Hwaseong; ${ }^{2}$ Department of \\ Plastic and Reconstructive Surgery, \\ Soonchunhyang University Bucheon \\ Hospital, Bucheon, Korea
}

The purpose of this study is to discuss several approaches to addressing naso-orbito-ethmoidal (NOE) fracture. Orbital fracture, especially infraorbital fracture, can be treated through the transconjunctival approach easily. However, in more severe cases, for example, fracture extending to the medial orbital wall or zygomatico-frontal suture line, only transconjunctival incision is insufficient to secure good surgical field. And, it also has risk of tearing the conjunctiva, which could injure the lacrimal duct. Also, in most complex types of facial fracture such as NOE fracture or panfacial fracture, destruction of the structure often occurs, for example, trap-door deformity; a fracture of orbital floor where the inferiorly displaced blowout facture recoils to its original position, or vertical folding deformity; fractured fragments are displaced under the other fragments, causing multiple-packed layers of bone.

Keywords: Fractures, multiple / Maxillary fractures / Orbital fractures / Surgical procedures

\section{BACKGROUND}

Naso-orbito-ethmoidal (NOE) fractures are complicated fractures of mid-face structure which include nasal, lacrimal, maxillary, frontal, and ethmoid bones. The central feature of NOE fracture is displacement of the medial orbital rim with the medial canthal ligament attached. The medial canthal tendon (MCT) splits before insertion into the frontal process of the maxilla. A fracture that separates the maxilla from the MCT attachment site results in fatal displacement.

This section has a unique feature that requires careful attention to return the fracture to its pre-injury state. One of the important goals of facial fracture treatment is to reconstruct the shape of the pre-traumatic face $[1,2]$. Another purpose is normal function recovery of facial structure [3].

Recent advances in reconstruction of the craniofacial skeleton

Correspondence: Yong Bae Kim

Department of Plastic and Reconstructive Surgery, Soonchunhyang University

Bucheon Hospital, 170 Jomaru-ro, Wonmi-gu, Bucheon 14584, Korea

E-mail: psyb@schmc.ac.kr

This work was supported by the Soonchunhyang University Research Fund.

Received May 22, 2019 / Revised July 22, 2019 / Accepted July 29, 2019 have introduced new surgical methods for NOE fracture. New approaches to these NOE fractures have been introduced that minimize scarring and facilitate fracture fragment reduction. The approaches include endoscopic, bone tissue engineering, and methods for modifying existing approaches. But each of these approaches has advantages and disadvantages. Thus, the choice of approach may vary depending on the nature of the fracture and preference of the physician. This review will discuss advancements in several approaches to NOE fracture.

\section{ETIOLOGY}

NOE fractures are common with blunt trauma and are most commonly caused by vehicular accidents and assaults [4-7]. Because NOE fractures occur due to high energy, they often occur with other facial fractures [8]. Approximately $60 \%$ of NOE fractures are associated with orbital fractures, and approximately $20 \%$ are diagnosed with panfacial fractures [9]. Isolated NOE fracture accounts for approximately $5 \%$ of all facial fractures in adults and $16 \%$ in pediatric facial fractures [10,11].

The MCT is separated before insertion into the frontal pro- 
cess of the maxilla. Anterior limbs are inserted in the anterior lacrimal gland in the frontal process of the maxilla while posterior limbs are inserted in the posterior lacrimal crest on the lacrimal bone. These two limbs of the tendon surround the lacrimal fossa and establish soft tissue boundaries around the lacrimal sac fossa.

Because of this structure, telecanthus often occurs in NOE fractures. Traumatic telecanthus is observed at all stages except the first stage of NOE fracture, and distance between MCTs is increased. The patient has a distinctive appearance of telecanthus. Eyes may appear far apart, as in orbital hypertelorism $[12,13]$. Traumatic orbital hypertelorism (as compared to telecanthus) is an deformity characterized by increase in distance between orbits and ocular globes [7].

Because NOE fractures usually occur with severe trauma, evaluation of other critical areas before fracture evaluation should be completed. Patients with ocular damage or suspected visual anomalies should undergo full ophthalmologic examination to dismiss damage associated with the visual system, such as traumatic optic neuropathy [14].

\section{DIAGNOSIS}

NOE fractures can cause symptoms such as facial edema, flattening of the malar region, hemorrhage, diplopia, enophthalmos, telecanthus, and loss of nasal support $[14,15]$. Epiphora is typically associated with up to $50 \%$ of NOE fractures caused by nasolacrimal duct obstruction, direct damage to the lacrimal gland, or soft tissue edema [16].

Several classification systems have been introduced to assess severity of injury and for planning the type of reconstruction. The first classification system, first described by Gruss [2] in 1985, classified NOE fractures into five types with descriptions of specific treatment methods for each impairment pattern. Currently, the most frequently used classification system was detailed by Markowitz et al. [3] in 1991 for grading injuries. Extent of injury in this system is based on the MCT position and state of the central bone segment.

\section{MANAGEMENT}

An important goal of facial fracture treatment is to reconstruct facial appearance to its previous state. It is thus important to choose an appropriate approach that exposes the fracture site.

Despite much progress, surgical approach to NOE or Le Fort II fractures requiring extensive access, has remained largely unchanged. Coronal approach remains the gold standard for complicated NOE fractures, but it may be too invasive to treat sim- ple NOE fractures, because of the need for large incisions. Additionally, it has risk of complications such as scalp paralysis, hair loss, and flap hematoma, and the operation is lengthy $[17,18]$. Also, if the fracture involves the lower level, coronal incision may not be sufficient to achieve the desired result [19].

To avoid these drawbacks, some authors have introduced a mid-facial degloving (MFD) approach that can provide an exposure of the entire mid-facial skeleton through the sublabial incision of the maxilla and expand to upper and lateral sides according to fracture extent. However, the MFD approach will also produce some nasal related complications, such as nasal cosmetic deformity, nasal obstruction, and temporary infraorbital anesthesia $[19,20]$.

Recently, an endoscopic approach has been introduced. This approach has the advantage of producing similar outcomes with only small incisions, reducing patient morbidity, shortening operation duration and shortening patients' recovery period. However, there remains a drawback in that additional instruments are needed and there is a learning curve [21].

In some cases, it may need additional skin incision such as infraorbital, subciliary, transconjunctival, and/or lateral rim incisions, which may lead to facial scarring [19]. A transcaruncular approach is often used, to access the nasofrontal suture. However, there were limitations in the possibility of injury to normal orbit structures, such as violating the posterior limb of the MCT, and limitation of surgical view. Sometimes a local cutaneous approach is used, but not often, unless it is a special case because of scarring [22-25]. The percutaneous MCT approach exposes the entire medial orbital wall, nose, and orbital apex by percutaneously with an incision of only $1.5 \mathrm{~cm}$ to $2.0 \mathrm{~cm}$, which is more cosmetically acceptable than a lynch incision [26].

In cases of accompanying zygomaticomaxillary complex fracture, lateral canthotomy is often performed with transconjunctival incision, if exposure of zygomaticofrontal suture is needed $[27,28]$. There is an advantage of providing a wider surgical field of view and less possibility of lacrimal duct injury, than conventional transconjunctival incision alone. However, scar formation is possible, and asymmetric palpebral fissure length can be achieved, if accurate repair of the lateral canthus is not performed [29]. To overcome these shortcomings, approaching the blow out fracture through transconjunctival approach with paracanthal incision has been introduced [30,31].

\section{CONCLUSION}

Various approaches have been introduced to treat NOE fractures. These methods are common in that they were developed with the purpose of achieving maximum surgical effectiveness 
with minimal scar. Because NOE fracture is not constant and various types of fractures occur, we should accurately locate the fracture site by using advanced imaging technology and choose an appropriate approach.

\section{NOTES}

\section{Conflict of interest}

No potential conflict of interest relevant to this article was reported.

\section{Ethical approval}

The study was approved by the Institutional Review Board of Soonchunhyang University Bucheon Hospital (IRB No. 201903-025) and performed in accordance with the principles of the Declaration of Helsinki. The informed consent was waived.

\section{ORCID}

Young In Ha

Sang Hun Kim

Eun Soo Park

Yong Bae Kim https://orcid.org/0000-0001-8999-6956

https://orcid.org/0000-0002-1907-2309

https://orcid.org/0000-0003-2966-9122

https://orcid.org/0000-0003-2750-608X

\section{REFERENCES}

1. He D, Zhang Y, Ellis E 3rd. Panfacial fractures: analysis of 33 cases treated late. J Oral Maxillofac Surg 2007;65:2459-65.

2. Gruss JS. Naso-ethmoid-orbital fractures: classification and role of primary bone grafting. Plast Reconstr Surg 1985;75:30317.

3. Markowitz BL, Manson PN, Sargent L, Vander Kolk CA, Yaremchuk M, Glassman D, et al. Management of the medial canthal tendon in nasoethmoid orbital fractures: the importance of the central fragment in classification and treatment. Plast Reconstr Surg 1991;87:843-53.

4. Baril SE, Yoon MK. Naso-orbito-ethmoidal (NOE) fractures: a review. Int Ophthalmol Clin 2013;53:149-55.

5. Rosenberger E, Kriet JD, Humphrey C. Management of nasoethmoid fractures. Curr Opin Otolaryngol Head Neck Surg 2013;21:410-6.

6. Cruse CW, Blevins PK, Luce EA. Naso-ethmoid-orbital fractures. J Trauma 1980;20:551-6.

7. Converse JM, Smith B. Naso-orbital fractures and traumatic deformities of the medial canthus. Plast Reconstr Surg 1966; 38:147-62.

8. Roden KS, Tong W, Surrusco M, Shockley WW, Van Aalst JA, Hultman CS. Changing characteristics of facial fractures treated at a regional, level 1 trauma center, from 2005 to 2010: an assessment of patient demographics, referral patterns, etiology of injury, anatomic location, and clinical outcomes. Ann Plast Surg 2012;68:461-6.

9. Becelli R, Renzi G, Mannino G, Cerulli G, Iannetti G. Posttraumatic obstruction of lacrimal pathways: a retrospective analysis of 58 consecutive naso-orbitoethmoid fractures. J Craniofac Surg 2004;15:29-33.

10. Kelley P, Crawford M, Higuera S, Hollier LH. Two hundred ninety-four consecutive facial fractures in an urban trauma center: lessons learned. Plast Reconstr Surg 2005;116:42e-49e.

11. Chapman VM, Fenton LZ, Gao D, Strain JD. Facial fractures in children: unique patterns of injury observed by computed tomography. J Comput Assist Tomogr 2009;33:70-2.

12. Mulliken JB, Kaban LB, Evans CA, Strand RD, Murray JE. Facial skeletal changes following hypertelorbitism correction. Plast Reconstr Surg 1986;77:7-16.

13. Tessier P, Guiot G, Rougerie J, Delbet JP, Pastoriza J. Cranionaso-orbito-facial osteotomies. Hypertelorism. Ann Chir Plast 1967;12:103-18.

14. Nguyen M, Koshy JC, Hollier LH Jr. Pearls of nasoorbitoethmoid trauma management. Semin Plast Surg 2010;24:383-8.

15. Buchanan EP, Hopper RA, Suver DW, Hayes AG, Gruss JS, Birgfeld CB. Zygomaticomaxillary complex fractures and their association with naso-orbito-ethmoid fractures: a 5-year review. Plast Reconstr Surg 2012;130:1296-304.

16. Gruss JS, Hurwitz JJ, Nik NA, Kassel EE. The pattern and incidence of nasolacrimal injury in naso-orbital-ethmoid fractures: the role of delayed assessment and dacryocystorhinostomy. $\mathrm{Br}$ J Plast Surg 1985;38:116-21.

17. Ellis E 3rd. Sequencing treatment for naso-orbito-ethmoid fractures. J Oral Maxillofac Surg 1993;51:543-58.

18. Manson PN. Facial fractures. In: Mathes SJ, editor. Plastic surgery. 2nd ed. New York: Elsevier; 2006. p. 77-381.

19. Cultrara A, Turk JB, Har-El G. Midfacial degloving approach for repair of naso-orbital-ethmoid and midfacial fractures. Arch Facial Plast Surg 2004;6:133-5.

20. Villwock JA, Suryadevara AC. Update on approaches to the craniomaxillofacial skeleton. Curr Opin Otolaryngol Head Neck Surg 2014;22:326-31.

21. Pham AM, Strong EB. Endoscopic management of facial fractures. Curr Opin Otolaryngol Head Neck Surg 2006;14:234-41.

22. Garcia GH, Goldberg RA, Shorr N. The transcaruncular approach in repair of orbital fractures: a retrospective study. J Craniomaxillofac Trauma 1998;4:7-12.

23. Shorr N, Baylis HI, Goldberg RA, Perry JD. Transcaruncular approach to the medial orbit and orbital apex. Ophthalmology 2000;107:1459-63.

24. Rodriguez J, Galan R, Forteza G, Mateos M, Mommsen J, Bou- 
so OV, et al. Extended transcaruncular approach using detachment and repositioning of the inferior oblique muscle for the traumatic repair of the medial orbital wall. Craniomaxillofac Trauma Reconstr 2009;2:35-40.

25. Choi M, Flores RL. Medial orbital wall fractures and the transcaruncular approach. J Craniofac Surg 2012;23:696-701.

26. Timoney PJ, Sokol JA, Hauck MJ, Lee HB, Nunery WR. Transcutaneous medial canthal tendon incision to the medial orbit. Ophthalmic Plast Reconstr Surg 2012;28:140-4.

27. Kushner GM. Surgical approaches to the infraorbital rim and orbital floor: the case for the transconjunctival approach. J Oral Maxillofac Surg 2006;64:108-10.

28. Rohrich RJ, Janis JE, Adams WP Jr. Subciliary versus subtarsal approaches to orbitozygomatic fractures. Plast Reconstr Surg 2003;111:1708-14.

29. De Riu G, Meloni SM, Gobbi R, Soma D, Baj A, Tullio A. Subciliary versus swinging eyelid approach to the orbital floor. J Craniomaxillofac Surg 2008;36:439-42.

30. Emam HA, Stevens MR, Larsen PE, Jatana CA. Lateral tarsotomy: a practical alternative to lateral canthotomy to increase orbital access. Oral Surg Oral Med Oral Pathol Oral Radiol 2016; 122:e1-4.

31. Suh YC, Choi JW, Oh TS, Koh KS. Analysis of extended transconjunctival approach with lateral paracanthal incision: a study among classical methods of orbital approach and new method. J Craniofac Surg 2016;27:2050-4. 